\title{
Ética e Bioética: O que os Alunos do Sexto Ano Médico Têm a Dizer
}

\author{
Ethics and Bioethics: What Sixth Year Medical \\ Students Have to Say
}

\author{
Aline Camargo \\ Margareth Aparecida Santini de Almeida ${ }^{I}$ \\ Ione Morital
}

PALAVRAS-CHAVE

- Ética;

- Bioética;

- Ética Médica;

- Estudantes de Medicina;

- Educação Médica.

\section{KEYWORDS}

- Ethics;

- Bioethics;

- Medical Ethics;

- Medical Students;

- Medical Education.

Recebido em: 23/02/2013

Reencaminhado em: 15/05/2014

Aprovado em: 23/06/2014

\section{RESUMO}

A formação ética e bioética é fundamental para a humanização do atendimento preconizada pela política de saúde no Brasil e para o desenvolvimento de um profissional crítico. Estudos recentes revelam que Ética e Bioética têm carga horária restrita nos cursos médicos. Ressalta-se, ainda, sua importância diante do grande número de denúncias contra médicos recebido pelos Conselhos Regionais de Medicina. O objetivo deste trabalho foi identificar a percepção sobre questões éticas e bioéticas dos alunos do sexto ano médico, que, portanto, logo estariam ingressando no mercado de trabalho. Foram entregues questionários autoaplicáveis com perguntas abertas e fechadas aototal de 93 matriculados, dos quais 70 responderam. Os alunos consideraram a formação curricular acadêmica e o exemplo prático dos professores como importantes fontes de aprendizado da Ética e Bioética. Este fato contrapõe-se à insatisfação quanto à forma de abordagem do tema na graduação. O estudo tornou evidente a existência de deficiências no ensino que devem ser supridas a fim de aprimorar a formação ética e a prática médica.

\section{ABSTRACT}

Ethical and bioethical training is essential to the humanization of care as recommended by Brazilian health policy and tothe development of a critically-minded professional. Recent studies have shown that ethics and bioethics are afforded limited class hours in medicinecourses. Their importance is also noteworthy in light of the high number of complaints against doctors that are received by the Regional Medical Councils. This study aimed at identifying the perception of sixthyear medical students concerning bioethical issues. Self-applicable questionnaires containing open-ended and closed-ended questions were presented to the students. Seventy out of ninety registered students answered them. Students considered curricular academic training and practical examplesgiven by teachers as important sources for learning ethics and bioethics. On the other hand, dissatisfaction was expressed regarding how the topic is approached in undergraduate courses. The study highlighted shortcomings in education which must be resolved in order to enhance ethical training and medical practice. 


\section{INTRODUÇÃO}

Neste novo milênio, questões éticas estão na pauta das discussões filosóficas, econômicas, políticas, na formação e atuação profissionais, enfim, em todos os campos do conhecimento, dada a complexidade da vida, que reflete as grandes determinações sociais, culturais e ideológicas. A ética implica um juízo crítico sobre valores, e, na prática profissional médica, não basta ser capaz de discernir o certo do errado. É necessário estabelecer limites legais para a regulamentação profissional, os quais estão elencados, para os médicos, no Código de Ética Médica(CEM) ${ }^{1}$. Num sentido mais amplo, deve-se refletir sobre os valores que se referem à vida e à saúde, portanto, sobre uma Bioética como parte do cotidiano de todos.

Entre as diversas influências, a da escola médica na formação ética e bioética é fundamental. Quando se observa que a reforma universitária de 1968 no Brasil foi marcada pela influência da Reforma Flexner, algumas questões ficam evidenciadas $^{2}$. Em suma, o modelo flexneriano impôs o envolvimento do ensino com as tecnologias vigentes, mas não atribuiu espaço às ciências humanas. Tampouco houve referência ao curso de Ética Médica, estabelecendo-se um modelo rígido, afastado do humanismo e da visão do ser humano como um todo. Isto levoua "especializações precoces" do aluno de graduação em um mercado de trabalho associado ao tradicional consultório, no qual há disponibilidade de instrumentos de diagnóstico e encaminhamentos. Essa limitação de visão enquanto médico, tecnicista, sem a capacidade de abordar o paciente como um ser biopsicossocial e a fragmentação do ensino podem ter criado a dificuldade de formar médicos generalistas ${ }^{2}$. Nesse sentido, Araújo ${ }^{3}$ conclui: “O que ganhamos em técnica perdemos em ética" (p.67).

A necessária revisão de tal formação, introduzida por outros movimentos reformistas, especificamente a Medicina Integral e Preventiva e a Medicina Comunitária ${ }^{4}$, implicou mudanças curriculares nas escolas ao longo das últimas décadas. Influencia-se, inclusive, a construção de diretrizes curriculares nacionais do curso de graduação em Medicina,que destacamo perfilde um profissional generalista, humanista, crítico e reflexivo. Espera-se, assim, formar um profissional que atue "pautado em princípios éticos" em todos os níveis de atenção e em todas as fases do processo saúde-doença, "na perspectiva da integralidade da assistência", contribuindo para o pleno desenvolvimento da cidadania ${ }^{5}$ (p.10). A relevância da formação ética e bioética aparece em vários itens que compõem a diretriz, como na definição das competências e habilidades, dentre as quais "realizar seus serviços dentro dos [...]princípios da ética/bioética", nos conteúdos curriculares, quando se enfatizacompreender os "determinantes [...] éticos e legais, nos níveis individual e coletivo, do processo saúde-doença", e na própria organização docurso, que deve, necessariamente, "incluir dimensões éticas e humanísticas, desenvolvendo no aluno atitudes e valores orientados para a cidadania" ${ }^{\prime \prime}$ (p. 10, 12 e 14).

Entende-se, assim,que a Ética Médica (não restrita apenas ao ensino do Código de Ética Médica) é fundamental para permear no estudante de Medicina a essencialidade política, pois o leva a reflexões e orientações quanto a seus deveres e à moral, evitando a alienação, não devendo se limitar apenas à teoria, sendo fundamental o exemplo prático dos professores-médicos aos alunos ${ }^{6}$. D'Ávila ${ }^{7}$ defende o ensino da Ética e Bioética para os estudantes de Medicina, para que não apenas seja adquirida a habilidade técnica, mas também, e igualmente importante, sejam incorporados o conhecimento e os valores éticos, sabidamente fundamentais à prática médica consciente e humana.

O Código de Ética Médica, instituído em 1988 no Brasil, passou por revisão em 2009 perante a necessidade de adaptações à realidade contemporânea, destacando-se as seguintes diretrizes: proibição aos médicos de recomendar tratamentos de forma a receber comissão de indústria farmacêutica e proibição de criação de embriões para pesquisa e de escolha do sexo do bebê em clínicas de reprodução humana ${ }^{1}$.

Há consciência de que o modelo de ensino médico deve ser repensado, para suprir as deficiências quanto à formação médica e se adequar às necessidades do cenário contemporâneo. Por isso, entende-se a transformação pela qual passa o ensino de Ética Médica nas escolas médicas brasileiras 8 . Apesar da evidente necessidade de mudanças na formação médica e da importância admitida do ensino da Ética, há, ainda, certa relutância em lhe conferir espaço no currículo por se acreditar que seja muito filosófico e pouco prático, despertando pouco interesse nos alunos ${ }^{3}$. O estudo "Reflexões sobre erro e educação médica em Minas Gerais" ${ }^{\prime \prime}$ revelou que, dentre as 26 instituições de ensino médico pesquisadas, apenas nove ofereciam a disciplina de Ética, oito ofereciam a disciplina de Bioética e três a disciplina de Deontologia. Nenhuma das instituições oferecia a disciplina de Responsabilidade Civil Médica. Tal realidade se confronta com o número crescente de casos de denúncias contra médicos sobre questões ético-disciplinares, as quais reforçam a tendência mundial da inserção da Ética Médica como disciplina obrigatória nos currículos da graduação médica ${ }^{10,11,12}$. Além disso, no campo da pesquisa, a atenção atribuída à Ética Médica eà Bioética também não recebe a devida importância. Carneiro et al. ${ }^{13}$ demonstraram que há escassez na publicação de artigos nacionais na área da saúde sobre a temática "ensino da Ética", segundo os critérios de inclusão do estudo. 
O período no qual se deve abordar a Ética Médica também é alvo de discussões ${ }^{1}$. No entanto, estudos curriculares da Ética Médica em 79 faculdades de Medicina, no Brasil, revelaram que, em 1992, havia a prevalência (40,5\%) da disciplina apenasno nível do quarto ano ${ }^{14}$. Estudos mais recentes revelaram que o espaço curricular da Ética Médica permanece desorganizado, como também persiste pouca carga horária em muitas das faculdades de Medicina do Brasil. Em trabalho de 2003, avaliou-se o ensino de Ética Médica em 103 escolas médicas brasileiras, mostrando-se que 93 ministram o curso, mas a grande maioria dentro da disciplina de Medicina Legal ${ }^{10}$.

Na instituição investigada, Bioética e Ética Médica não é abordada como uma disciplina independente, mas como matéria integrante da disciplina de Saúde Coletiva, distribuída ao longo do primeiro (4 horas-aula), segundo (4 horas-aula), terceiro (20 horas-aula) e sexto (14 horas-aula)anos de graduação. Portanto, são 42 horas-aula em seis anos de curso médico dedicado à discussão de Ética Médica e Bioética, o que não impede que tais questões surjam em diferentes situações, como na discussão do tema aborto ${ }^{15}$, mas sem registro oficial. Destaca-se que a abordagem desse conteúdo resultou de reforma curricular no final da década de 1990 em meio ao movimento das escolas médicas da América Latina, que passaram a ter as necessidades de saúde como objeto.

Dadas as questões acima e a importância dessa formação para o desenvolvimento de um profissional crítico, com reflexos para um melhor atendimento na área da saúde, é que se propôs este estudo com futuros médicos.

\section{MÉTODOS}

O universo de pesquisa compreendeu os alunos que estavam cursando o sexto ano de Medicina (n=93)de uma faculdade do interior do Estado de São Paulo em 2010.Optou-se pela participação dos alunos do sexto ano neste estudo, pois, desta forma, seria possível avaliar o efeito do ensino ao longo de toda a graduação e as opiniões e conhecimentos dos futuros médicos que ingressarão no mercado de trabalho.

Após o projeto ser submetido e aprovado pelo Comitê de Ética em Pesquisa da instituição (OF. 064/2010-CEP), os questionários foram entregues aos alunos do sexto ano por grupo de internato, quando se reuniam em sala para assistirem à aula. Foram esclarecidos os objetivos e lido o termo de consentimento livre e esclarecido, tendo-se livre escolha de responder ou não. Do total de 93 alunos, 70 responderam $(75,3 \%)$, e os demais estavam ausentes (19) ou se abstiveram (4). Com perguntas fechadas e algumas abertas, fez-se uma análise descritiva, utilizando-se as respostas abertas para explicar ou justificar os dados encontrados.O questionário foi elaborado com o objetivo de estabelecer o perfil dos alunos e do ensino de Ética e Bioética na instituição, as deficiências desse conhecimento por parte dos sextanistas, o nível de interesse e as opiniões acerca do ensino e das vivências. Mesmo se restringindo à formação local, este estudo pretende somar-se à discussão existente na literatura sobre formação ética e bioética.

Dessa forma, é possível que outras faculdades de Medicina também possam refletir sobre a qualidade e suficiência da abordagem do tema. Esse cenário tem impacto sobre a formação de médicos conscientes e responsáveis em sua prática profissional, e, consequentemente, leva a uma população mais bem assistida.

\section{RESULTADOS E DISCUSSÃO}

A Tabela 1 apresenta a caracterização dos alunos em relação a idade e sexo. Do total de 70 alunos, 57,1\% tinham entre 2024 anos, evidenciando que ingressaram na faculdade com a média de idade de 19 anos, além de haver um predomínio de mulheres nesta série $(58,5 \%)$. Tais resultados são semelhantes aos obtidos por Taquette et al. ${ }^{16}$ quanto à faixa etária jovem na qual ingressam na faculdade. Os autores também encontraram predomínio de jovens do sexo feminino no curso de Medicina, tendência já apontada por Bruschini e Lombardi ${ }^{17}$, que em 1996 encontraram que 38\% dos médicos brasileiros eram do sexo feminino. Este aumento da inserção de mulheres no mercado de trabalho médico consolida-se nos anos recentes: em 2009, entraram mais mulheres do que homens no mercado; em 2011, dos 48.569 médicos com 29 anos ou menos, $53,31 \%$ eram mulheres ${ }^{18}$.

\section{TABEla 1}

Distribuição dos alunos do sexto ano da Faculdade de Medicina de Botucatu por faixa etária e sexo. Botucatu, 2010

\begin{tabular}{clclccc}
\hline \multirow{2}{*}{$\begin{array}{c}\text { Faixa etária/ } \\
\text { sexo }\end{array}$} & \multicolumn{2}{c}{ Masculino } & \multicolumn{2}{l}{ Feminino } & \multicolumn{2}{c}{ Total } \\
\cline { 2 - 7 } & $\mathbf{N}$ & $\mathbf{\%}$ & $\mathbf{N}$ & & $\mathbf{N}$ & $\%$ \\
\hline $20-24$ & 18 & 25,7 & 22 & 31,4 & 40 & 57,1 \\
$25-31$ & 11 & 15,8 & 19 & 27,1 & 30 & 42,9 \\
\hline Total & 29 & 41,5 & 41 & 58,5 & 70 & 100,0 \\
\hline
\end{tabular}

A maioria (58,6\%) afirmou ter lido o Código de Ética Médica. No entanto, considera-se significativo o percentual de alunos que não o leram $(41,4 \%)$, apesar de estarem no sexto ano médico e prestes a entrarem no mercado de trabalho, fatores que aumentam a relevância do número encontrado. Esses dados contrastam com os obtidos por Vieira e Neves ${ }^{19}$, em que apenas $4 \%$ dos alunos do segundo ao sexto ano de Medicina 
responderam que nunca fizeram uma leitura do Código de Ética Médica.

Para esses $41,4 \%$ que nunca leram o CEM, sugere-se que não dão importância ao tema porque talvez não tenham absorvido e compreendido adequadamente a ética abordada na graduação. Nesse sentido, deve haver problemas na estrutura curricular, que não se apresenta com carga horária suficiente e é desenvolvida segundo modelos e conteúdos pouco apreendidos pelos alunos, o que contribui para afastar o aluno do tema.

A abordagem deficiente durante a graduação também pode ser responsável por não instigar o aluno a se interessar pelo tema e a compreender sua importância e essência, o que pode justificar a alta porcentagem de alunos que nunca leram o CEM.

Quando questionados se acompanham discussões sobre Ética Médica e Bioética, 32 alunos (45,7\%) responderam positivamente e 38 (54,3\%) não responderam (Tabela 2). Entre aqueles que referiram acompanhar esse tema, 11 alunosincluíram as próprias aulas de graduação, o que seria curricular e não avaliaria o interesse pelo tema em si, tendo-se, assim, um percentual significativo que não procura leituras e discussões por meio das categorias listadas (congresso, revistas científicas, televisão, internet e outros). Chama-se atenção para o acesso à internet e à televisão, que, juntas, foram indicadas por 15 alunos(21,4\% do total) e cuja presença é uma importante ferramenta como tecnologia em informação, devendo-se estar atento ao seu conteúdo.

\section{TABELA 2}

Distribuição percentual em relação ao acesso aos meios de discussão sobre ética adotado pelos alunos do sexto ano da FMB. Botucatu, 2010 (respostas múltiplas)

\begin{tabular}{|c|c|}
\hline Categoria & $\%$ \\
\hline Congresso & 8,6 \\
\hline Revistas científicas & 4,3 \\
\hline Televisão & 11,4 \\
\hline Internet & 20,0 \\
\hline Aulas médicas & 10,0 \\
\hline Palestras e encontros & 1,4 \\
\hline $\begin{array}{l}\text { Discussão com colegas da área médica e outras áreas, } \\
\text { como de Ciências Humanas }\end{array}$ & 1,4 \\
\hline
\end{tabular}

A busca pelo tema por meio de palestras, encontros e discussões com colegas da área médica e de outras áreas, como ciências humanas, não foi destacada, pois apenas dois alunos mencionaram essa opção.Destacou-se a área de humanas porque, de fato, não se deve desvincular a Ética Médica e Bioética das ciências humanas, tal como defendem $\operatorname{Rego}^{20}$ e Carson ${ }^{21}$, com a inclusão "desde a literatura clássica e moderna até a psicologia, direito, filosofia e ética". O estudo "O lugar da Ética e Bioética nos currículos de formação médica"22também defende a importância de realizar uma abordagem multidisciplinar do tema, com a presença de professores formados em Ciências Sociais e Ciências Humanas (como Filosofia, Psicologia e Letras). Tal multidisciplinaridade contribuiria para uma formação menos tecnicista e mais humanista, já que o aprendizado se voltaria para uma visão multidisciplinar e interdisciplinar do processo saúde-doença.

Os resultados sugerem que a graduação poderia instigar tal interesse por meio de uma abordagem adequada. Dessa forma, a aceitação e o domínio do tema seriam maiores, e talvez aumentasse o percentual de alunos que buscasse o tema extracurricularmente.

A falta de interesse em estudar extracurricularmente o tema contrasta com a percepção que a maioria dos alunos demonstrou em outras questões sobre a importância de saber ética e bioética na profissão. Sem dúvida, as causas são multifatoriais, mas a atuação da escola médica é fundamental quanto à abordagem da Ética e Bioética, devendo estimular e instigar o aluno a buscar e a se aprofundar no tema. Como os próprios alunos enfatizaram, há ausência de uma disciplina independente, e uma alta porcentagem delesconsiderou a abordagem do tema insuficiente $(79,7 \%)$ e a metodologia inadequada.

Foi, então, solicitado aos alunos que dessem sugestões de como o conteúdo de Ética Médica e Bioética deveria ser desenvolvido. Transcrevem-se algumas respostas:

"As aulas em auditório são muito ruins e entediantes. Deveriam ocorrer em pequenas aulas, junto com outros temas. Por exemplo: sobre aborto na Obstetrícia; sobre medicina do trabalho/atestados em saúde pública,etc".

\footnotetext{
"Deveria ser desenvolvido a partir do debate de situações reais, que ocorreram com outros colegas(médicos), que saíram nos jornais, por exemplo".

"Exposição de casos clínicos cuja situação ou atuação ética gera dúvidas, com discussão posterior".
}

Muitos alunos sugeriram casos clínicos e casos do dia a dia como principal alvo para o ensino, pois isso aumentaria o interesse, a participação e a própria importância dada ao tema, já que sentiriam que seu conhecimento é fundamental para uma prática médica bem amparada. Discute-se, ainda, a importância 
de grupos pequenos para discussão dos casos de conflito ético, o que contrasta com palestras e aulas com toda a turma que predominam durante o ensino de Ética e Bioética na instituição.

Silva et al. ${ }^{23}$ comprovam que a mudança da metodologia do ensino da Ética e Bioética é capaz de modificar a percepção, a motivação e o interesse dos alunos por meio de novas estratégias (introdução de debates, filmes, dramatizações e participação de profissionais de outras áreas, como psicólogos e antropólogos),permitindo, inclusive, a capacidade de lidar com dilemas éticos.Para os autores, o novo modelo foi capaz de obter avaliações positivas dos alunos, contrapondo-se às avaliações do modelo passado, então caracterizado como "desestimulante" e "sem propósito".

Questionados sobre influências na sua formação ética e bioética, 45 alunos (64,3\%) mencionaram a família, 33 (47,1\%) a própria formação curricular acadêmica, 31 (44,3\%) o exemplo prático de professores e médicos, e 20 (28,6\%) a religião (Tabela 3). A influência familiar, somada à religião,confirma o proposto por Gomes ${ }^{22}$, para quem o estudante de Medicina inicia a formação acadêmica carregando sua bagagem informal de preceitos, herdada da educação familiar, escolar, religiosa e social.

\section{TABELA 3}

Distribuição dos alunos segundo fonte de influência na formação em ética e bioética (múltipla escolha).

Botucatu, 2010

\begin{tabular}{lc}
\hline Categorias & $\%$ \\
\hline Formação familiar & 82,8 \\
Formação curricular acadêmica & 47,1 \\
Religião & 37,1 \\
Exemplo prático dos professores e médicos da FMB & 61,4 \\
Outros & 1,4 \\
\hline
\end{tabular}

Destacou-se a formação curricular acadêmica $(47,1 \%)$ e o exemplo prático dos professores e médicos $(44,3 \%)$, o que revela a consciência dos alunos quanto à importância da graduação para sua preparação ética na profissão. Em pesquisa realizada por Serodio e Almeida ${ }^{24}$, em que 237 docentes responderam sobre as situações de conflito ético consideradas mais relevantes para a discussão com os alunos, os relacionamentos professor-paciente-aluno, professor-aluno, professor-professor e aluno-aluno foram mencionados como importantes tópicos a serem discutidos. Tal resultado expõe que alunos e professores reconhecem a importância da relação professor-aluno na aprendizagem da Ética Médica. Portanto, a ela devem ser dedicadas discussões para que seja aprimorada, permitindo a real qualidade do ensino.

Este aspecto remete à ideia de que deve haver uma boa preparação pelos professores, para que conduzam atitudes e dilemas éticos de maneira apropriada, de forma a constituírem bons exemplos para os alunos. Tal expectativa, contudo, contrasta com o estudo de Vieira e $\mathrm{Neves}^{19}$, que revelou despreparo, desconhecimento e desinteresse dos professores envolvidos no estudo.

Portanto, diante da porcentagem de alunos (44,3\%)que se referem aos professores como exemplos de conduta, deve-se estimular a atualização nestas questões, pois são influências diretas na qualidade da formação dos alunos para saberem abordar dilemas éticos e conduzir seu futuro cotidiano profissional de forma ética.

A orientação ética e bioética segundo a religião mostra a complexidade do tema e dos julgamentos. Vale destacar que "A formação médica está longe de se restringir a uma atividade 'asséptica' de transmissão de conhecimentos ou de capacitação técnica" ${ }^{25}$ (p.5303). Portanto, é compreensível que o entendimento de ética seja uma constituição de origem multifatorial. Não se espera que a ética acadêmica curricular seja responsável por todo comportamento médico, mas que, em dadas ocasiões, direcione, conduza e clarifique suas atitudes no contexto médico-paciente.

$\mathrm{O}$ aluno também foi questionado segundo questões baseadas no Código de Ética Médica (CEM), devendo assinalar $\mathrm{V}$ (verdadeiro) ou $\mathrm{F}$ (falso)conforme seuconhecimento(Tabela 4).Ressalta-se, aqui, a baixa porcentagem obtida em questões fundamentais para o exercício consciente da prática médica. Como exemplo, a não compreensão da relação médico-Código de Ética Médica quanto ao fato de ser punitivo (acerto de apenas $15,7 \%$ ), para aqueles que estão prestes a ingressar no mercado de trabalho, indicando desconhecimento da relação direitos-deveres que ampara a própria profissão.

Também chama a atenção que, embora 57,1\% dos alunos tenham acertado que o CEM proíbe aliciamento para clínicas particulares de pacientes atendidos em instituições públicas, $42,9 \%$ o ignoram. Por outro lado, apenas $28,6 \%$ indicaram corretamente que o CEM aborda questões relativas aos laboratórios farmacêuticos, sendo estes tão polêmicos na realidade médica. Tal porcentagem é preocupante, pois os laboratórios farmacêuticos permeiam negativamente a relação médico-paciente. Não raro, o médico pode desconsiderar a realidade socioeconômica do paciente para receitar o medicamento proposto pela indústria farmacêutica, em troca de benefícios próprios. Considera-se que entender esta situação é de importância fundamental. 
TABELA 4

Distribuição dos alunos segundo acertos de questões do Código de Ética Médica. Botucatu, 2010

\begin{tabular}{ll} 
Questões do Código de Ética Médica & $\begin{array}{c}\text { Porcentagem } \\
\text { de acertos }\end{array}$ \\
\hline
\end{tabular}

Diante de doador vivo interdito ou incapaz, o

médico pode retirar órgão em havendo autorização 55,7

do responsável legal. (F)

O CEM é punitivo. (V)

O CEM atual foi elaborado em 1988 e desde então não sofreu alterações. $(\mathrm{F})$

Segundo o CEM, o médico deve ser solidário aos movimentos de defesa da dignidade profissional. (V)

O CEM aborda diretamente os atestados ilegíveis. (V)

É permitido ao médico remunerar ou receber comissão por pacientes encaminhados. (F)

O CEM proíbe o aliciamento para clínicas particulares de pacientes atendidos em instituições públicas. (V)

O CEM proíbe o médico de dar consultas, diagnósticos ou prescrições por meio de veículos de comunicação de massa. (V)

O CEM trata diretamente de laboratórios farmacêuticos. (V)

Não deve haver segredo médico perante paciente menor de idade, podendo o médico informar pais ou responsáveis legais, sob qualquer circunstância. (F)

O CEM proíbe a criação de embriões para pesquisa e a escolha do sexo do bebê em clínicas de reprodução humana. (V)

(V) ou (F) após as afirmações são as respostas esperadas.

Conclui-se, portanto, que falta preparo, tanto quanto a não leitura do CEM, como também quanto à interpretação e aplicação das leis apreendidas. Esses alunos, com mau entendimento das leis que regem a profissão, é que estarão ingressando no mercado de trabalho e poderão em breve se deparar com alguma situação, com a qual, diante de conhecimentos insuficientes, não saberão lidar adequadamente e dentro das leis regidas pelo CEM. Quanto àquelas questões com altas porcentagens de acertos, nenhuma, no entanto, atingiu 100\%. Neste sentido, há alunos que não saberiam lidar com a situação ou, ao menos, analisá-la corretamente. A meta deve ser que todos os alunos compreendam corretamente o conjunto de leis que determina a medicina, sua profissão. Além da compreensão e aplicação do CEM, os alunos também devem se tornar profis- sionais aptos a lidar com situações mais complexas, que não se encontram nas páginas do CEM. A capacidade de manejar dilemas éticos (que não necessariamente albergam o certo ou errado) é de extrema importância para a prática médica e, portanto, também deve ser destacada nas discussões de atualização dos currículos médicos.

Questionou-se, ainda, se o aluno havia vivenciado uma situação que considerou eticamente conflituosa. Eis algumas respostas:

"Mãe não havia contado ao filho pré-adolescente que era HIV positivo".

"Presenciei pacientes serem tratados com desrespeito por professores".

"Paciente em atendimento no pronto-socorro... desejava que eu cobrasse alguma quantia dela para oferecer um pedido de exame de raios $X$ de tórax. Logicamente, não o vendi".

"Tentativa de aborto proposital em que se deve respeitar o sigilo da paciente".

"Em um ambulatório, um professor comunicou uma má notícia (paciente portador de câncer) de forma desrespeitosa e faltou sensibilidade e acolhimento ao paciente".

"Já presenciei episódios em que médicosatenderam pacientes particulares utilizando a estrutura/aparato tecnológico do hospital, o que eu considero antiético".

Neste tópico,não foi julgado se as respostas eram ou não de conflito ético, mas, sim, quanto à percepção de cada aluno que expôs seu relato. Os relatos demonstram sensibilidade ao reconhecerem situações eticamente conflituosas e ao questionarem a respeito. Aponta-se, ainda, que nem sempre a equipe profissional e docente segue a melhor conduta ética - aqueles que, de fato, deveriam constituir modelos para os alunos.

Destaca-se, também, a referência à problemática clássica das Testemunhas de Jeová e que, apesar de ser uma situação recorrente, muitos não saberiam lidar com ela.

Muitos dos temas mencionados pelos alunos podem apontar a dificuldade que teriam para resolver determinada situação; a sensibilidade em reconhecê-la; a importância que o evento assumiu para eles. Portanto, tais situações devem ser tomadas como exemplo no momento da abordagem junto aos alunos. Em pesquisa realizada por Serodio e Almeida ${ }^{24}$, ao serem indagados quanto aos temas de maior relevância a serem abordados com os acadêmicos de Medicina, professores 
mencionaram os mesmos temas levantados pelos alunos deste estudo. Dentre os semelhantes, destacam-se a importância da relação médico-paciente e o relacionamento professor-paciente-aluno. Isto pode refletir um ponto positivo, em que alunos e professores almejam um mesmo objetivo, o que, sem dúvida, é um grande passo para um ensino de qualidade.

Tais informações induzem ao questionamento quanto à necessidade de uma supervisão que auxilie o aluno a conduzir tais situações ou, mesmo, à necessidade de uma supervisão "mais ética" por parte dos docentes.

Tais relatos são de fundamental importância para guiar as discussões durante a graduação, pois são vivenciados pelos alunos, e estes gostariam de ser orientados sobre como agir, pois não se sentem aptos a lidar com situações eticamente conflituosas. Isto, com certeza, traria os alunos para dentro da esfera da Ética Médica e da Bioética, fazendo brotar interesses e conhecimentos práticos e efetivos para os alunos.

\section{CONCLUSÃO}

Este trabalho revelou que a maioria dos alunos do sexto ano médico envolvidos na pesquisa considera o tema importante e não acompanha discussões de ética e bioética extracurricularmente. $\mathrm{O}$ interesse extracurricular deve ser ressaltado porque a maioria considera insuficiente a abordagem recebida e, logo, não se sente bem amparada pelo currículo. Embora um percentual expressivo considere os professores e médicos como exemplos a serem seguidos quanto à conduta ética na profissão, relatos de situações eticamente conflituosas se referema má conduta, denunciando o desgaste da qualidade humanista e da relação médico-paciente dos profissionais. Vale lembrar que o ambiente onde se dá o processo de ensino tem grande influência na conduta moral do aluno (Bredemeier, Shields apud Serodio e Almeida ${ }^{24}$ ), e, portanto, "o engajamento do docente pode tornar tal ambiente mais ou menos adequado à opção por atos moralmente desejáveis" ${ }^{\prime 24}$ (p.60).

Assim, dar mais espaço no currículo para a Ética e a Bioética não será suficiente se os professores não seguirem os preceitos ditados pelo CEM e pela própria conduta solidária frente ao paciente. Por outro lado, os alunos representam um campo fértil, pois ainda cobram pelo atendimento humanitário e questionam realidades maiores. Tal perfil cria a expectativa de que os alunos aceitariam e absorveriam com interesse a abordagem da Ética e da Bioética na graduação. Portanto, os relatos de situações eticamente conflituosas revelaram a sensibilidade dos alunos em questionar o seu meio, além de demonstrarem situações com as quais não saberiam lidar. Tal preocupação aflora na consciência dos alunos a necessidade de aprofundar a abordagem na graduação.
Somando os dados obtidos - a consciência da importância e necessidade de conhecer a ética na profissão, a baixa porcentagem que busca estudar o tema, as baixas porcentagens de acerto em questões essenciais do CEM-, concluímos que a implementação da Ética Médica e da Bioética na grade curricular é evidente e necessária. Tais dados sugerem uma formação ética insuficiente, pois o aluno não conhece as leis e regras que ditam a própria profissão e não se sente preparado para resolver um caso de conflito ético, amparando-se em seus próprios conceitos morais para tomar decisões (como, por exemplo, aceitar ou não uma proposta de uma indústria farmacêutica) e resolver conflitos.

Conclui-se, ainda, que se deve repensar o modelo de ensino adotado para o tema ética médica e bioética,em razão das críticas recebidas. Os alunos consideraram que as aulas tradicionais de auditório não são produtivas, sugerindo que o tema deveria ser abordado em grupos pequenos, que permitissem discussões de melhor qualidade, além de contato mais próximo com o professor. Além disso, muitos sugeriram basear os temas em casos reais, atendidos por eles mesmos, ou, se fictícios, casos com que poderão se deparar em algum momento da vida profissional. Assim, se sentiriam mais bem amparados para resolver eventuais problemas de ordem ética.

\section{AGRADECIMENTO}

À Fundação de Amparo à Pesquisa do Estado de São Paulo (Fapesp), pelo auxílio financeiro.

\section{REFERÊNCIAS}

1. Soares CS, Cavalcanti EFA. [Internet]. Destaques do novo Código de Ética Médica [capturado 11 dez. 2009]. Disponível em: http://www.medicinanet.com.br/conteudos / artigos/2359/destaques_do_novo_codigo_de_etica_medica.htm.

2. Neves NC. Ética para os futuros médicos. É possível ensinar? Brasília: Conselho Federal de Medicina; 2006.

3. Araújo RWB. A ética do ensino médico e o ensino da Ética Médica. In: Assad JE, Liberal PSP, Freitas Jr HL. Desafios éticos. Brasília: CFM; 1993 [capturado 11 dez. 2009]. Disponível em:http://www.portalmedico.org.br/include/ biblioteca_virtual/des_etic/desafios_etc.htm

4. Cyrino EG, Rizzato ABP. Contribuição à mudança curricular na graduação da Faculdade de Medicina de Botucatu. RevBras Saúde MaternInfant2004;4(1): 59-69.

5. Brasil. Ministério da Educação. Conselho Nacional de Educação. Diretrizes Curriculares Nacionais do Curso de Graduação em Medicina. Brasília; 2001.

6. Nicholas B. Power and the teaching of medical ethics. J MedEthics 1999;25(6): 507-13. 
7. D’Ávila RL. A Ética Médica e a Bioética como requisitos do ser moral: ensinando habilidades humanitárias em medicina. Rev Bioética 2010;18(2):311-27.

8. Siqueira JE, Sakai MH, Eisele RL. O ensino da ética no curso de Medicina: a experiência da Universidade Estadual de Londrina (UEL). Rev Bioética Ética Méd 2002;10(1):85-95.

9. Ribeiro WC, Julio RS. Reflexões sobre erro e Educação Médica em Minas Gerais. Rev Bras Educ Med 2011;35(2):2637.

10. Muñoz D, Muñoz DR. O ensino da Ética Médica nas faculdades de Medicina do Brasil. Rev Bras Educ Med 2003;27(2):114-24.

11. D’Ávila RL. É possível ensinar Ética Médica em um curso formal curricular? Rev Bioética Ética Med2002;10(1):11-26.

12. Grisard N. Ética Médica e Bioética: a disciplina em falta na graduação médica.Rev Bioética Ética Méd 2002;10(1):97-114.

13. Carneiro LA, Porto CC, Duarte SBR, Chaveiro N, Barbosa MA. O ensino da Ética nos cursos de graduação da área de saúde. Rev Bras Educ Med 2010; 34(2):412-21.

14. Meira AR, Cunha MMS. O ensino da ética médica em nível de graduação nas faculdades de Medicina do Brasil. Rev Bras Educ Med 1994;18(1):7-10.

15. Almeida MAS, Barbosa FHR, França IA, Morita I. Legislação brasileira relativa ao aborto: o conhecimento na formação médica. Rev Bras Educ Med 2012; 35(2):243-8.

16. Taquette SR, Rego S, Schramm FR, Soares LL, Carvalho SV. Situações eticamente conflituosas vivenciadas por estudantes de medicina. Rev Assoc Med Bras 2005;51(1):23-8.

17. Bruschini C, Lombardi MR. Médicas, arquitetas, advogadas e engenheiras: mulheres em carreiras, profissionais de prestígio. Rev Estud Fem 1999;7(1-2):9-24.

18. Conselho Regional de Medicina do Estado de São Paulo. Demografia médica no Brasil. São Paulo.2011;1:18-20.

19. Vieira PSPG, Neves NMBC. Ética Médica e Bioética no curso médico sob o olhar dos docentes e discentes. Mundo da Saúde 2009;33(1):21-5.
20. Rego S. A formação ética dos médicos: saindo da adolescência com a vida (dos outros) nas mãos. Rio de Janeiro: Fiocruz; 2003.

21. Carson R. Teaching ethics in the context of medical humanities. J Med Ethics 1994;20(1):235-8.

22. Gomes AMA, Moura ERF, Amorim RF. O Lugar da Ética e Bioética nos currículos de formação médica. Rev Bras Educ Med 2006;30(2):56-65.

23. Silva J, Leão MHM, Pereira ACAC. Ensino de bioética na graduação de medicina: relato de experiência. Rev Bioética 2013;21(2):338-43

24. Serodio AMB, Almeida JAM. Discussão de situações de conflito ético. Rev Bras Educ Med2009;33(1):55-62.

25. Oliveira AM. Bioética e as diretrizes curriculares nacionais do curso de medicina. RevBras Saúde MaternInfant 2010;10(3):5303-9.

\section{CONTRIBUIÇÃO DOS AUTORES}

Margareth A.S. de Almeida reviu e sugeriu as alterações necessárias para atender ao parecer.

Ione Morita analisou, reviu e introduziu as alterações sugeridas pelo parecer.

Aline Camargo participou de todas as etapas desde a formulação do projeto até a revisão final.

\section{CONFLITO DE INTERESSES}

Declaramos não haver conflito de interesses.

\section{ENDEREÇO PARA CORRESPONDÊNCIA}

Ione Morita

Departamento de Saúde Pública / Faculdade de Medicina de Botucatu/ UNESP

Botucatu - São Paulo

CEP: 18.618-970 - SP

E-mail: alinecamargo08@yahoo.com.br 